\title{
Mechanical and thermal studies of unsaturated polyester-toughened epoxy composites filled with amine-functionalized nanosilica
}

\author{
Y. Jaya Vinse Ruban · S. Ginil Mon • \\ D. Vetha Roy
}

Received: 24 August 2011 / Accepted: 14 February 2012/Published online: 2 March 2012

(C) The Author(s) 2012. This article is published with open access at Springerlink.com

\begin{abstract}
The inter-crosslinking networks of unsaturated polyester (UP)-toughened epoxy-nanosilica hybrid nanocomposites have been developed. Epoxy resin was toughened with 5 and $10 \%$ (by wt) of unsaturated polyester using benzoyl peroxide as radical initiator and 4,4'-diaminodiphenylmethane (DDM) as a curing agent at appropriate condition, and the resulting product was identified by FT-IR spectra. Unsaturated polyestertoughened epoxy system (10\%) was further filled with 1 , 3,5 and $7 \%$ (by wt) of amine-functionalized nanosilica particles prepared by sol-gel method. Modified nanosilica-filled hybrid UP-epoxy matrices developed in the form of casting were characterized for their thermal, mechanical properties and water absorption capacity according to ASTM standards. The degree of dispersion of nanosilica in the matrices was investigated by SEM technique. Mechanical testing data indicate that the introduction of UP into epoxy resin has improved the impact strength. Significant improvement in the flexural properties, tensile properties and impact strength were observed in the UP-epoxy blends with increase in the percentage of amine-modified nanosilica particles. The $T_{\mathrm{g}}$ value decreases with UP toughening and increases with concentration of modified nanosilica on the UP-epoxy matrix. The water absorption behavior is found to decrease with UP toughening and concentration of modified nanosilica on the UP-epoxy matrix.
\end{abstract}

Y. Jaya Vinse Ruban $(\bowtie) \cdot$ S. Ginil Mon · D. Vetha Roy Department of Chemistry and Research, Polymer

Nanocomposite Centre, Scott Christian College (Autonomous), Nagercoil 629003, Tamilnadu, India

e-mail: jayavinse@gmail.com
Keywords Epoxy · Unsaturated polyester .

Sol-gel method · Amine-nanosilica . Thermal property . Mechanical properties - Water absorption .

Nanocomposites

\section{Introduction}

Epoxy resins are widely used mainly due to their thermal, mechanical, chemical and corrosion resistance. A favorable property of epoxy resins is the low viscosity in the uncured state that enables the resin to be processed without the use of high pressure equipments. The main drawback of epoxy systems is their inherent brittleness. Most of the techniques for toughness improvement are based on the addition of rubbers or thermoplastic modifiers (Cicala and Recca 2008). However, modification of epoxy resin with elastomers improved its impact properties with degradation in some of the physical properties at high temperature regions (Preghenella et al. 2005).

The addition of nanoparticles has exhibited high potential for proven mechanical properties of polymers. Battistella et al. (2008) obtained an increase of 54\% of fracture toughness by filling an epoxy resin with $0.5 \mathrm{vol} \%$ of fuming silica modified with 3-aminopropyltrimethoxy silane. Ragosta et al. (2005) found that adding $10 \mathrm{wt} \%$ of $\mathrm{TiO}_{2}$ nanoparticles within epoxy resin increased fracture toughness by a considerable percentage. Zhanhu Guo et. al. (2007) studied the effect of functionalized $\mathrm{ZnO}$ nanoparticle on the optical and mechanical properties of vinyl resin. Zhang and Singh (2004) established that $\mathrm{Al}_{2} \mathrm{O}_{3}$ (micro-nano) particles enhance the fracture toughness with polyester matrix, strongly influenced by the particle matrix adhesion.

Hussain et al. (2007) obtained an increase of $47 \%$ of the tensile modulus in filling an epoxy with $5 \mathrm{wt} \%$ of clay. Choi et al. (2005) obtained a maximum tensile strength and 
Young's modulus resulting in 5 wt $\%$ of cup-stacked carbon nanotubes filling in epoxy. Chisholm et al. (2005) observed an average of $20-30 \%$ increase in mechanical properties with $1.5 \mathrm{wt} \%$ loading of carbon/SiC on epoxy resin. Rajulu et al. (2003) used epoxy and polyester as coating materials and observed that alkali-treated epoxy and polyester-coated fibers showed an increase in tensile strength of 55 and $88 \%$, respectively, over the uncoated fibers.

The present work attempts to improve the mechanical behavior of epoxy resin by toughening with unsaturated polyester and reinforcing the toughened matrix with aminemodified nano silica particles.

\section{Experimental}

Materials

Unsaturated polyester resin (isophthalic acid based) with viscosity 2,300-2,400 cP and analytical-grade benzoyl peroxide were supplied by Polyresins, India. Diglycidyl ether of bisphenol-A (DGEBA) by Ciba-Geigy Ltd., India was used as the epoxy resin. 4, 4'-Diaminodiphenylmethane (DDM) obtained from Ciba-Geigy Ltd. was used as curing agent. Aminopropyldiethoxysilane and tetraethoxysilane (TEOS) were supplied as gift samples by Anabond Limited, Chennai. Dry toluene, methanol and ammonium hydroxide were provided by the Central Drug House, New Delhi. De-ionized water was used throughout the study.

Preparation of silica nanoparticles

Methanol as medium and ammonium hydroxide as catalyst were mixed in $2-\mathrm{L}$ resin kettle, followed by dropwise addition of TEOS in methanol, carried out for $3 \mathrm{~h}$ at room temperature. The particles obtained were centrifuged and de-ionized water was added to remove the catalyst. The washed powder was vacuum dried at $100^{\circ} \mathrm{C}$ for 3 days (Huimin $\mathrm{Lu}$ et al. 2006) and further heated to $600^{\circ} \mathrm{C}$ for $30 \mathrm{~min}$ and then to $1,000^{\circ} \mathrm{C}$ for $2 \mathrm{~h}$ in a muffle furnace.

Modification of silica surface with amine group

Ten grams of the synthesized silica particles was mixed with $120 \mathrm{ml}$ of the solution of aminopropyldiethoxysilane in toluene. The silica powder was centrifuged, washed repeatedly with toluene and cured at $150^{\circ} \mathrm{C}$ in vacuum for $6 \mathrm{~h}$.

Preparation of hybrid unsaturated polyester-toughened epoxy resin

A fixed amount of epoxy resin (100 g), varying amounts of unsaturated polyester resin (5 and $10 \mathrm{~g}$ ), a stoichiometric amount of melted DDM (27.2 g) with respect to epoxy resin, and benzoyl peroxide ( $2 \mathrm{wt} \%$ ) with respect to unsaturated polyester, were mixed with constant stirring. The hybrid product was then degassed to remove the entrapped air and then transferred into a preheated mold kept at $100^{\circ} \mathrm{C}$ for $4 \mathrm{~h}$ and post-cured at $140^{\circ} \mathrm{C}$ for $3 \mathrm{~h}$.

Preparation of amine-modified silica/UP/epoxy nanocomposites

The epoxy resin (100 g) was mechanically mixed with the desired amount of amine-modified silica particles (1, 3, 5 and $7 \%$ ) at $80^{\circ} \mathrm{C}$ for $24 \mathrm{~h}$ and sonicated for $30 \mathrm{~min}$. To the above nanosilica-filled epoxy resin, $10 \mathrm{~g}$ of unsaturated polyester resin and benzoyl peroxide were added ( $2 \mathrm{wt} \%$ ) at $50^{\circ} \mathrm{C}$ for $10 \mathrm{~min}$ with constant stirring. A stoichiometric amount of curative DDM (27.2 g) corresponding to epoxy equivalents was heated and added to the above mixture at $80^{\circ} \mathrm{C}$. The product was subjected to vacuum for removing the trapped air and then casted and vacuum cured at $100^{\circ} \mathrm{C}$ for $4 \mathrm{~h}$. The casting was then post-cured at $140^{\circ} \mathrm{C}$ for $3 \mathrm{~h}$ and finally released from the mold and then characterized.

\section{Characterization}

The IR spectra were recorded on a Perkin-Elmer (Model RX1) FT-IR spectrometer, with $\mathrm{KBr}$ pellets. Glass transition temperature $\left(T_{\mathrm{g}}\right)$ of the samples was determined using a DSC Netzsc (TA instruments, USA) in the temperature range $50-250^{\circ} \mathrm{C}$ at a heating rate of $10^{\circ} \mathrm{C}$ per min in nitrogen atmosphere. The tensile (stress-strain) properties were determined using INSTRON (model 3365, UK) as per ASTM D 3039 at $10 \mathrm{~mm} \mathrm{~min}^{-1}$ cross-head using specimen with a width of $25 \mathrm{~mm}$, length of $200 \mathrm{~mm}$ and thickness of $3 \mathrm{~mm}$. The flexural (strength and modulus) properties were measured (INSTRON, model 3365, UK) as per ASTM D 790 using specimen with dimensions $3 \mathrm{~mm}$ in depth, $10 \mathrm{~mm}$ in width and $90 \mathrm{~mm}$ in length at $10 \mathrm{~mm} \mathrm{~min}^{-1}$ cross-head speed. The unnotched Izod impact strength of each sample was studied as per ASTM D 256. All these parameters were arrived at as a mean of six samples.

The water absorption behavior of the samples was tested as per ASTM D 570. The cured specimens (dimensions: 60-mm square, 3-mm thickness) were immersed in distilled water for $48 \mathrm{~h}$. Specimens were removed and the surface water was removed using a tissue paper and weighed to an accuracy of $0.001 \mathrm{~g}$. The morphology of fractured surface of the samples was scanned using scanning electron microscope (SEM; JEOL JSM Model 6360). 


\section{Results and discussion}

\section{FT-IR spectroscopy}

The characteristic IR absorption peaks observed for nanosilica and amine-modified nanosilica are shown in Fig. 1. Figure 1a shows that on heating the silica particles up to $1,000^{\circ} \mathrm{C}$, most of the silanol groups are eliminated leading to the only peak of $-\mathrm{Si}-\mathrm{O}-\mathrm{Si}-\left(1,100 \mathrm{~cm}^{-1}\right)$. A broad band (in Fig. 1b) between 3,100 and $3,700 \mathrm{~cm}^{-1}$, related to the presence of $\mathrm{Si}-\mathrm{OH}$ and $-\mathrm{NH}_{2}\left(\mathrm{Si}-\mathrm{NH}_{2}\right)$, was detected. The band at around $1,100 \mathrm{~cm}^{-1}$ is attributed to the $-\mathrm{Si}-\mathrm{O}-\mathrm{Si}-$ bond stretching in the tetrahedral unit of the $\mathrm{SiO}_{2}$ matrixes (Huimin Lu et al. 2006). The signal at $1,648 \mathrm{~cm}^{-1}$ is due to the bending vibration of water molecules adsorbed on the silica surface.

Figure 2 is the FT-IR spectra of the epoxy resin and the $10 \mathrm{wt} \%$ unsaturated polyester-modified epoxy resin. The strong IR absorption peak due to the $\mathrm{C}=\mathrm{C}$ stretching of aromatic ring occurred at $1,611 \mathrm{~cm}^{-1}$ (Fig. 2a, b). The peaks at $2,965 \mathrm{~cm}^{-1}$ represent the aliphatic $\mathrm{C}-\mathrm{H}$ stretching of epoxy and UP-epoxy resin (Fig. 2a, b). An asymmetric stretching of methylene occurs at $2,929 \mathrm{~cm}^{-1}$ (Fig. 2a, b). The broad peaks at around $3,400-3,500 \mathrm{~cm}^{-1}$ indicate the presence of hydroxyl group of epoxy resin (Fig. 2a, b) and the peaks between 920 and $770 \mathrm{~cm}^{-1}$ suggest the presence of asymmetric stretching of the epoxide ring. The $914 \mathrm{~cm}^{-1}$ is strongly attributed to the stretching absorption of $\mathrm{C}-\mathrm{O}$ in the epoxide ring (Fig. 2a) and this absorption clearly disappeared after curing (Fig. 2b). The network structure formed between UP and epoxy resin shows the reaction of epoxide ring of epoxy resin with the hydroxyl group of unsaturated polyester and is further confirmed by

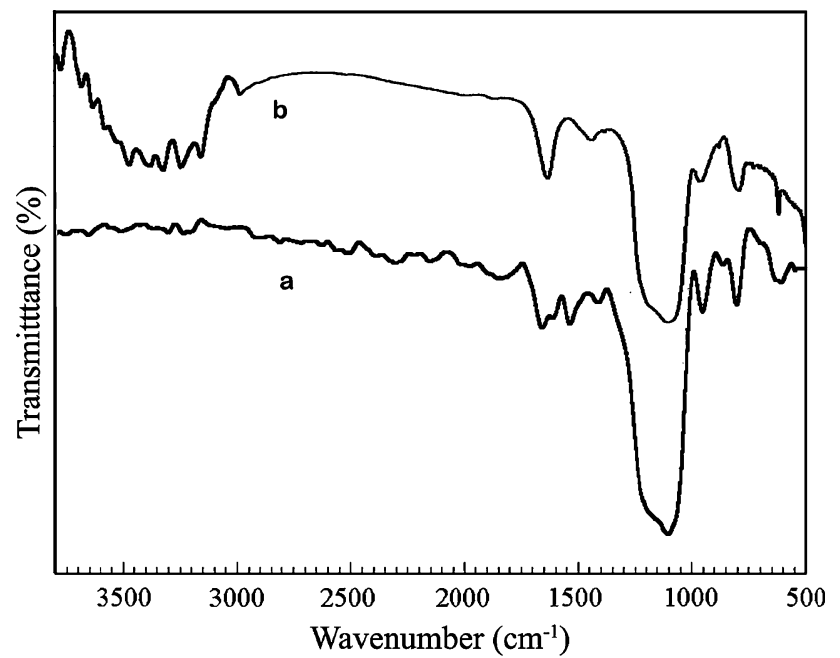

Fig. 1 FT-IR spectra nanosilica (a) and amine functionalized nanosilica (b) the decrease in the intensity of the epoxy band at $914 \mathrm{~cm}^{-1}$ (Ashok Kumar et al. 2001).

Thermal property

The glass transition temperature $\left(T_{\mathrm{g}}\right)$ of unmodified epoxy and UP-toughened epoxy systems are presented in Table 1. The value of the glass transition temperature of the epoxy system is decreased, with increasing concentration of UP. This is explained by the chain lengthening and flexibility behavior of unsaturated polyester resin, which in turn decreases the effective crosslink density and accelerates the reaction rate and reduces the curing temperature. This creates excess free volume and chain entanglement in the matrix system, leading to reduction in the values of $T_{\mathrm{g}}$, since $T_{\mathrm{g}}$ is associated with mobility of the molecule (Brown et al. 2000). The incorporation of amine-modified nanosilica into UP-toughened epoxy systems increased the glass transition temperature. The increase in the values of $T_{\mathrm{g}}$ is due to the reaction between the amine group of nanosilica and the epoxy resin and enhanced the curing temperature (Kang et al. 2001). This could be due to the effective crosslinking of amine-modified nanosilica with the UP-toughened epoxy resulting in the formation of nanocomposites.

\section{Mechanical properties}

The observed values for tensile and flexural properties of unmodified epoxy, UP-toughened epoxy and amine-modified silica-filled UP-toughened epoxy are presented in Table 2. The introduction of 5 and $10 \%$ of UP (by wt) into

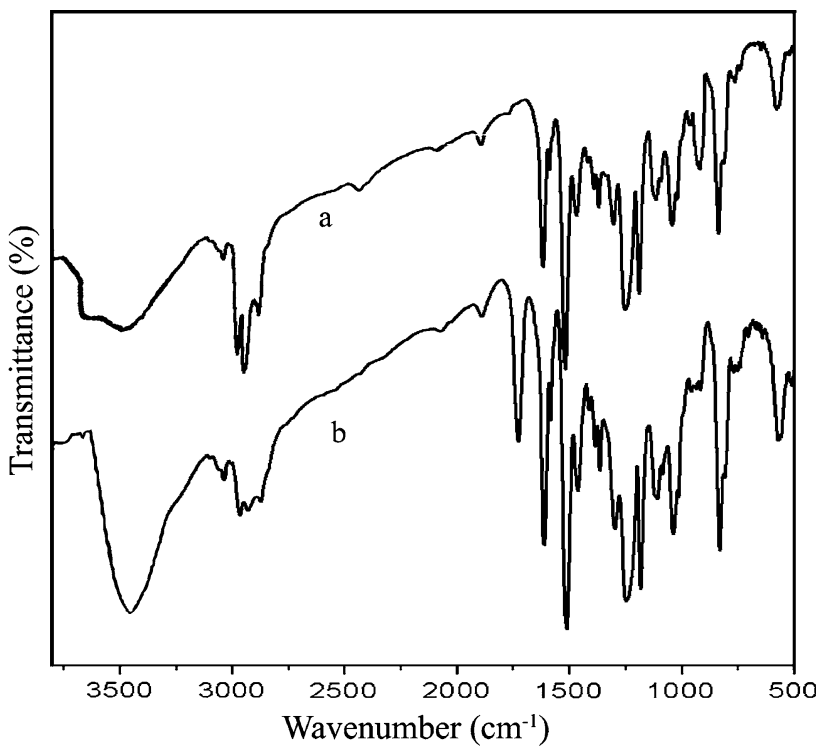

Fig. 2 FT-IR spectra of unmodified epoxy resin (a) and UPtoughened epoxy matrix cured by DDM with the composition (100:10) (b) 
Fig. 3 SEM images of a neat epoxy, b UP-toughened epoxy, c 1 wt $\%$ amine-silica/UP/epoxy, d $5 \mathrm{wt} \%$ amine-silica/UP/epoxy
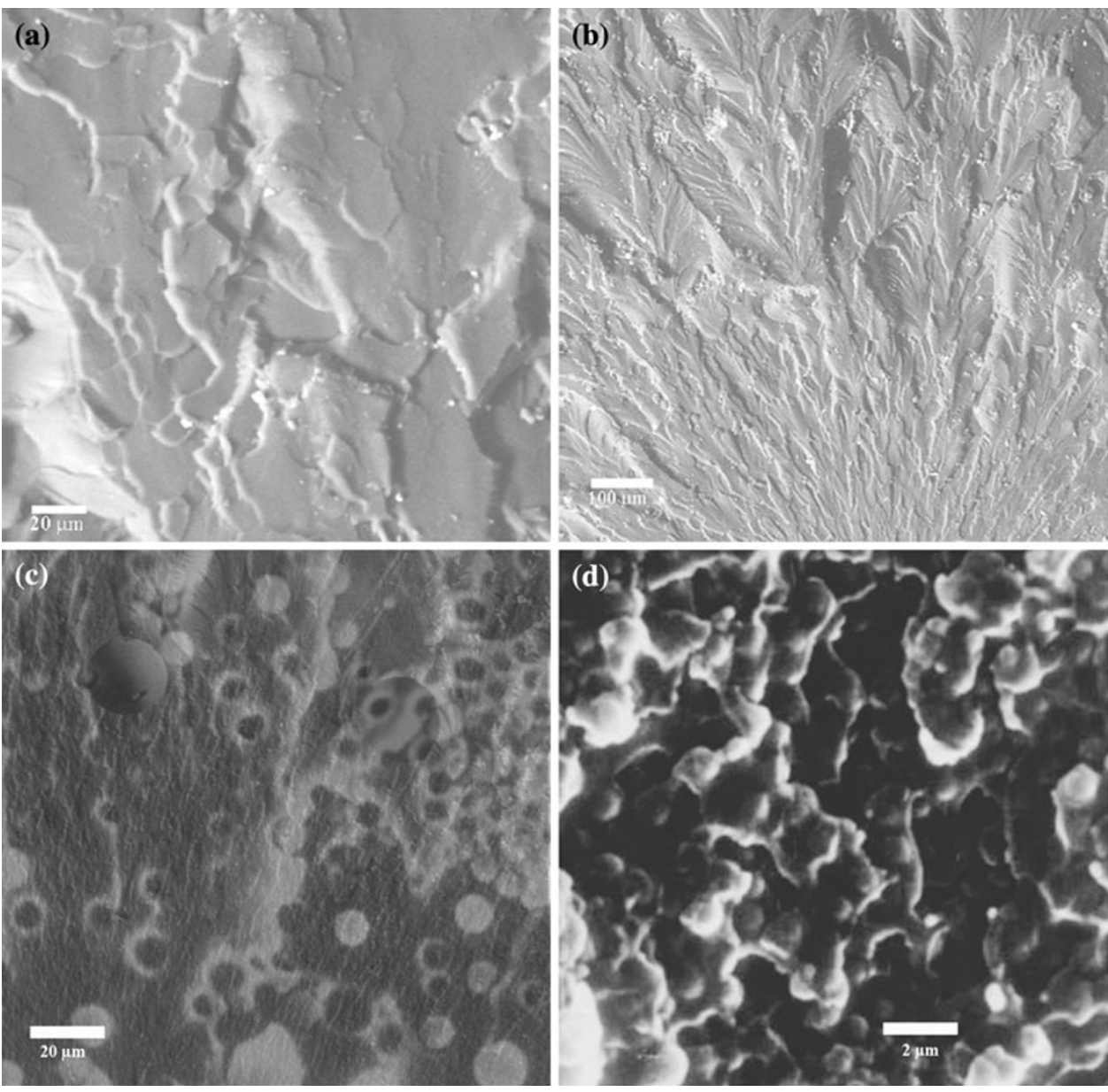

Table 1 Glass transition temperature of hybrid UP-epoxy nanocomposites

\begin{tabular}{ll}
\hline $\begin{array}{l}\text { Epoxy/UP/modified silica } \\
\text { composition }\end{array}$ & $\begin{array}{l}\text { Glass transition temperature } \\
\left({ }^{\circ} \mathrm{C}\right)\end{array}$ \\
\hline $100 / 00 / 00$ & 168 \\
$100 / 05 / 00$ & 151 \\
$100 / 10 / 00$ & 144 \\
$100 / 10 / 01$ & 150 \\
$100 / 10 / 03$ & 159 \\
$100 / 10 / 05$ & 164 \\
$100 / 10 / 07$ & 167 \\
\hline
\end{tabular}

epoxy resin decreased the tensile strength (3.6 and 7.4\%) and flexural strength (2.5 and $7.9 \%$ ), compared to the unmodified epoxy resin, due to the formation of chain entanglement in the UP-epoxy matrix system (Chozhan et al. 2007). The introduction of amine-modified nanosilica particles on UP-epoxy matrix improved the values of tensile strength and flexural strength according to their percentage content (Table 2). The introduction of 1, 3, 5 and $7 \%$ (by wt) amine-modified nanosilica into $10 \%$ UP-toughened epoxy resin increased the tensile strength
(9.4, 17.2, 24.9 and $28.5 \%)$ and flexural strength (11.8, 18, 29.2 and $38.2 \%$ ). Like tensile and flexural strength, the values of tensile and flexural modulus also follow a similar trend (Table 2).

The incorporation of 5 and 10\% (by wt) UP into epoxy resin enhanced the impact strength to 5.1 and $14.7 \%$ according to the percentage concentration of UP, due to the formation of entangled network structure developed in the unsaturated active sites of polyester-toughened epoxy system. Further, the incorporation of modified silica into the UP-epoxy systems also increased the impact strength due to the flexibility imparted by the plasticization effect of modified silica (Table 2). The introduction of 1, 3, 5 and $7 \%$ (by wt) modified silica into 10\% UP-toughened epoxy resin increased the impact strength to $17,27.4,34.5$ and $43.3 \%$, respectively. The loss of tensile and flexural strength/modulus of epoxy matrices due to the addition of UP was overcome by the addition of modified silica.

\section{Water absorption}

The incorporation of unsaturated polyester into epoxy resin decreased the percentage water uptake, according to the 
Table 2 Mechanical properties of hybrid UP-epoxy nanocomposites

\begin{tabular}{llllll}
\hline $\begin{array}{l}\text { Epoxy/UP/modified } \\
\text { silica }\end{array}$ & $\begin{array}{l}\text { Tensile strength } \\
(\mathrm{MPa})\end{array}$ & $\begin{array}{l}\text { Tensile modulus } \\
(\mathrm{MPa})\end{array}$ & $\begin{array}{l}\text { Flexural strength } \\
(\mathrm{MPa})\end{array}$ & $\begin{array}{l}\text { Flexural modulus } \\
(\mathrm{MPa})\end{array}$ & $\begin{array}{l}\text { Impact strength } \\
(\mathrm{J} / \mathrm{m})\end{array}$ \\
\hline $100 / 00 / 00$ & 67.3 & $2,807.17$ & 109.4 & $1,858.79$ & 102.43 \\
$100 / 05 / 00$ & 64.9 & $2,710.17$ & 106.7 & $1,822.43$ & $1,743.73$ \\
$100 / 10 / 00$ & 62.3 & $2,619.05$ & 100.8 & $2,075.17$ & 117.49 \\
$100 / 10 / 01$ & 73.6 & $3,051.44$ & 122.3 & $2,199.42$ & 119.76 \\
$100 / 10 / 03$ & 78.9 & $3,278.69$ & 129.1 & $2,411.20$ & 130.49 \\
$100 / 10 / 05$ & 84.1 & $3,510.61$ & 141.3 & $2,569.79$ & 149.72 \\
$100 / 10 / 07$ & 86.5 & $3,641.67$ & 151.2 & & \\
\hline
\end{tabular}

Table 3 Water absorption of hybrid UP-epoxy nanocomposites

\begin{tabular}{ll}
\hline Epoxy/UP/modified silica composition & Water absorption $(\%)$ \\
\hline $100 / 00 / 00$ & 0.1341 \\
$100 / 05 / 00$ & 0.1279 \\
$100 / 10 / 00$ & 0.1201 \\
$100 / 10 / 01$ & 0.1194 \\
$100 / 10 / 03$ & 0.1072 \\
$100 / 10 / 05$ & 0.0947 \\
$100 / 10 / 07$ & 0.0639
\end{tabular}

percentage concentration (Table 3) due to its inherent hydrophobic nature. Further, the incorporation of modified silica into epoxy and UP-toughened epoxy systems also reduced the percentage water uptake due to reduction in permeability behavior influenced by the nanocomposite structure.

\section{Morphology}

Comparison of the SEM images (Fig. 3a, b) of the surfaces of nanocomposites, UP-toughened epoxy and neat epoxy matrix shows that the epoxy and unsaturated polyester are strongly interconnected with no major macroscopic phase separation revealing a smooth, glassy and homogeneous microstructure without any plastic deformation. The image of fractured surfaces of unsaturated polyester-modified epoxy matrices filled with $1 \%$ (by wt) amine-modified silica nanoparticles shows a uniform dispersion of particles in the matrix and that the particles are in nanometer scale (Fig. 3c). The silica particles present are in spherical shape with an average particle size of $300-400 \mathrm{~nm}$.

\section{Conclusion}

Unsaturated polyester-toughened epoxy matrix systems with varied concentration were developed. Mechanical studies inferred that the incorporation of unsaturated polyester into epoxy resin enhanced their impact strength. Amine-modified nanosilica/UP/epoxy nanocomposites were prepared. The incorporation of amine-modified silica into UP-epoxy matrices steadily improved the tensile, flexural and impact strength and exhibited good resistance to water absorption. The incorporation of amine-modified silica into UP-epoxy matrix greatly improved the glass transition temperature. The SEM images of the epoxy and unsaturated polyester-modified epoxy matrix strongly reveal smooth, glassy and homogeneous microstructure without plastic deformation and an equal dispersion of nano-sized fillers on the matrix. The hybrid amine-modified nanosilica-filled UP-epoxy matrix systems developed in the present work can be used to fabricate advanced composite components for engineering and airspace applications for better performance.

Open Access This article is distributed under the terms of the Creative Commons Attribution License which permits any use, distribution, and reproduction in any medium, provided the original author(s) and the source are credited.

\section{References}

Ashok Kumar A, Alagar M, Rao R (2001) Preparation and characterization of siliconized epoxy/bismaleimide ( $N, N^{\prime}$-Bismaleimido-4,4'-diphenyl methane) intercrosslinked matrices for engineering applications. J Appl polym Sci 81:38-46

Battistella M, Cascione M, Fiedler B, Wickmann MHG, Quaresimin M, Schulte K (2008) Fracture behavior of fumed silica/epoxy nanocomposites. Compos Part A 39:1851-1858

Brown JM, Curliss D, Vaia RA (2000) Thermoset-layered silicate nanocomposites. Quaternary ammonium montmorillonite with primary diamine cured epoxides. Chem Mater 12:3376

Chisholm N, Mahfuz H, Rangari V, Ashtaq A, Jeelani S (2005) Fabrication and mechanical characterization of carbon/SiCepoxy nanocomposites. Compos struct 67:115-124

Choi YK, Gotoh Y, Sugimoto K, Song S, Yanogisawa T, Endo M et al (2005) Processing and characterization of epoxy nanocomposites reinforced by cup-stacked carbon nanotubes. Polymer 46:11489-11498

Chozhan CK, Alagar M, Sharmila RJ, Gnana Sundaram P et al (2007) Thermo mechanical behavior of unsaturated polyester toughened epoxy-clay hybrid nanocomposites. J Polym Res 14:319-328

Cicala G, Recca G (2008) Studies on epoxy blends modified with a hyperbranched polyester. Polym Eng Sci 48:2382-2388 
Guo Z, Wei S, Shedd B, Scafforo R, Pereira T, Hahn HT (2007) Particle surface engineering effects on the mechanical, optical and photoluminescent properties of $\mathrm{ZnO} /$ vinyl ester resin nanocomposites. J Mater Chem 17:806-813

Hussain F, Chen J, Hojjati M (2007) Epoxy silicate nanocomposites: cure monitoring and characterization. Mat Sci Eng A 445-446:467-476

Kang S, Hong S, Choe CR, Park M, Rim S, Kim J (2001) Preparation and characterization of epoxy composites filled with functionalized nanosilica particles obtained via sol-gel process. Polymer $42: 879-887$

Lu H, Xu X, Li X, Zhang Z et al (2006) Morphology, crystallization and dynamic mechanical properties of PA66/nano- $\mathrm{SiO}_{2}$ composites. Bull Mater Sci 29:485
Preghenella M, Pegoretti A, Migliaresi C (2005) Thermo-mechanical characterization of fumed silica-epoxy nanocomposites. Polymer 42:12065-12072

Ragosta G, Abbate M, Musto P, Scarinzi G, Mascia L (2005) Epoxysilica particulate nanocomposites: chemical interactions, reinforcement and fracture toughness. Polymer 46:10506-10516

Rajulu AV, Devi L, Rao G, Reddy R (2003) Chemical resistance and tensile properties of epoxy/unsaturated polyester blend coated bamboo fibers. J Reinf Plast Compos 22:1029-1034

Zhang M, Singh RP (2004) Mechanical reinforcement of unsaturated polyester by $\mathrm{Al}_{2} \mathrm{O}_{3}$ nanoparticles. Mater Lett 58:408-412 